\title{
Jean-Pierre Perchellet, L'héritage classique. La tragédie entre 1680 et 1814
}

\section{Franco Piva}

\section{Q OpenEdition \\ 1 Journals}

\section{Edizione digitale}

URL: http://journals.openedition.org/studifrancesi/34693

DOI: 10.4000/studifrancesi.34693

ISSN: 2421-5856

\section{Editore}

Rosenberg \& Sellier

\section{Edizione cartacea}

Data di pubblicazione: 1 novembre 2005

Paginazione: 417

ISSN: 0039-2944

\section{Notizia bibliografica digitale}

Franco Piva, «Jean-Pierre Perchellet, L'héritage classique. La tragédie entre 1680 et 1874», Studi Francesi [Online], 146 (XLIX | II) | 2005, online dal 30 novembre 2015, consultato il 19 avril 2021. URL: http:// journals.openedition.org/studifrancesi/34693 ; DOI: https://doi.org/10.4000/studifrancesi.34693

Questo documento è stato generato automaticamente il 19 avril 2021.

\section{(c) (i) (9)}

Studi Francesi è distribuita con Licenza Creative Commons Attribuzione - Non commerciale - Non opere derivate 4.0 Internazionale. 


\title{
Jean-Pierre Perchellet, L'héritage classique. La tragédie entre 1680 et 1814
}

\author{
Franco Piva
}

\section{NOTIZIA}

JEAN-PIERRE PERCHELLET, L'héritage classique. La tragédie entre 1680 et 1814, Paris, H.

Champion, 2004 («Les Dix-huitième siècles», 85), pp. 405.

1 È noto come il Settecento sia stato, quanto e forse più del Seicento, il secolo del teatro e della tragedia in particolare: dal punto di vista quantitativo, non si sono mai prodotte altrettante tragedie, malgrado per quasi tutto il secolo il solo luogo in cui esse potevano essere rappresentate sia stata la Comédie-Française che nel periodo preso in esame ha tuttavia messo in scena più di trecento nuovi testi, con una media, ineguagliata, di tre all'anno. Dal punto di vista della considerazione, la tragedia resta il genere nobile per eccellenza sia per chi lo pratica, sia per chi va a teatro, e Dio sa quanto il teatro è stato importante per il XVIII secolo: «c'est bien elle [la tragédie] qui permet d'accéder à la gloire littéraire par un coup d'éclat, attire les foules au théâtre, fait l'objet d'analyses minutieuses dans les journaux», osserva giustamente Jean-Pierre Perchellet. Ma è altrettanto noto quanta poca attenzione la storiografia letteraria abbia riservato al genere, ed il sostanziale disinteresse che ha avvolto la tragedia francese prodotta dopo Racine. Il celebre verso di Hugo («Sur Racine mort, le Campistron pullule») ha come paralizzato la critica, che si è mostrata incapace per lunghissimi anni di vedere nella tragedia settecentesca null'altro che una sempre più sterile imitazione della tragedia raciniana, o classica in genere, che una lenta e quasi patetica agonia o, al massimo, un'altrettanto lenta e faticosa preparazione del dramma romantico, attraverso quelle forme bastarde ed ibride che furono il drame bourgeois prima, il melodramma poi. La storia della tragedia settecentesca sarebbe, ad ogni modo, quella di un vuoto compreso tra i due incontournables punti di riferimento che sono, da un lato, la Phèdre di Racine, dall'altro l'Hernani di Hugo. 
2 Il puntuale studio di Jean-Pierre Perchellet proprio questo vuoto intende riempire: da un lato facendo vedere come il Settecento non si sia limitato a tentare di riprodurre, autant que possible, il modello raciniano, che se è certamente presente (né poteva essere diversamente) non è stato né subito né supinamente accettato; dall'altro, come il Settecento abbia prodotto una sua teoria della tragedia che non coincide con quella messa a punto dai teorici classici e praticata da Corneille e da Racine, che ha anzi una sua propria fisionomia che trova la sua ragion d'essere nelle trasformazioni ideologiche e nelle tensioni spirituali che caratterizzarono il secolo, e che trovarono espressione, oltre che nella tragedia, anche in altre forme espressive, come la pittura, la scultura, la scrittura e l'arte in genere; sicché le vivaci discussioni che animarono, ed in parte trasformarono la tragedia settecentesca, trovano la loro ratio non tanto nel rispetto dovuto ai modelli classici quanto nelle tensioni che attraversarono il secolo e di cui la tragedia non poteva non tener conto, e non farsi in qualche modo, e nonostante il peso del passato, via via espressione.

Ciò appare evidente dalle analisi che l'autore ha condotto, sulle 54 tragedie da lui prese in considerazione sulla base ad un'attenta selezione, sui diversi aspetti che la tragedia settecentesca comporta. Se il punto di partenza, di riferimento e di confronto è costituito sempre (talvolta in maniera anche troppo insistita) dalla dottrina classica, risulta chiaro che le animate discussioni dei teorici settecenteschi e che i tentativi degli autori miravano sì a liberare la tragedia settecentesca dall'ingombrante fardello classico, ma obbedivano sopratutto ad altre motivazioni, legate assai più al presente che al passato. Sicché la tragedia settecentesca è da vedere molto più come il frutto di uno sviluppo autonomo che il risultato di un faticoso confronto con un passato che certamente è esistito ma che ha condizionato il presente della tragedia assai meno di quanto non abbia fatto il presente stesso. Ne risulta l'immagine di una tragedia certamente più autonoma e più interessante; di una tragedia che è passata progressivamente da quella raciniana al dramma romantico attraverso un persorso che non è stato solo di difesa bensì di evoluzione e di trasformazione, spesso cosciente $\mathrm{e}$ coscientemente assunta; l'immagine insomma di una tragedia troppo méconnue, che non solo ha interesse a farsi meglio conoscere, ma che anche lo studioso settecentesco, e non solo quello del teatro, ha interesse a conoscere meglio per conoscere meglio anche il secolo che l'ha prodotta, secolo che, questa ne è l'ennesima riprova, non può più essere letto con le categorie letterarie e mentali con le quali per troppo tempo è stato presentato ed interpretato. Il libro di Perchellet, al di là di qualche schematismo $\mathrm{e}$ di qualche conclusione discutibile, ha i meriti per far nascere questo interesse e per attrarre sulla tragedia settecentesca quella curiosità critica che fino ad ora sono mancati. 